\title{
Muğla İlinde Son 5 Yılda Taranan Prematüre Bebeklerdeki Prematüre Retinopatisi Sonuçlarının Değerlendirilmesi
}

\section{Evaluation of the Results of the Retinopathy of Prematurity in the Babies Prematurly Born in Mugla Province}

\author{
Göksu ALAÇAMLI' ${ }^{1}$, Sema TAMER KADERL $\dot{I}^{1}$, Aylin KARALEZL $\dot{I}^{2}$, Nilay HAKAN ${ }^{3}$ \\ ${ }^{1}$ Muğla Eğitim ve Araştırma Hastanesi, Göz Hastalıkları Kliniği, Muğla \\ ${ }^{2}$ Muğla Sıtkı Koçman Üniversitesi Tıp Fakültesi Göz Hastalıkları Anabilim Dalı, Muğla \\ ${ }^{3}$ Muğla Sitkı Koçman Üniversitesi Tıp Fakültesi Yenidoğan Bilim Dalı, Muğla
}

\begin{abstract}
$\ddot{\text { Öz }}$
Muğla ilinde, prematür doğum öyküsüyle Prematüre Retinopatisi taraması için kliniğimize başvuran ya da yönlendirilen bebeklerdeki prematüre retinopatisi sonuçlarını değerlendirmek. 32 hafta altında gestasyonel yaşı olan bebeklerin tümü ile 32 hafta üstünde olan ve neonatolog ya da pediatrist tarafindan klinik olarak riskli bebek olarak değerlendirilen tüm bebekler tarandi. 2014-2019 yılları arasında toplam 486 bebeğe, 949 mükerrer muayene yapıldı. Prematüre retinopatisi, herhangi bir evrede $\% 8$ olarak tespit edildi. Tedaviye ihtiyaç duyan bebek sayısı sadece 1 idi. Prematüre retinopatisine bağlı körlüklerin önüne geçebilmek için, en ideal yöntem, risk grubundaki bebeklerin, standart bir çerçeve içinde taranmasıdır. Bu şekilde, tedavi gerektirecek bebeklerin zaman kaybetmeden etkili şekilde tedavisi ile prematüre retinopatisine bağlı körlükler önlenebilir.
\end{abstract}

Anahtar Kelimeler: Evreleme, Prematüre Retinopatisi, Takip

\section{Giriş}

Prematüre retinopatisi (PR), çocukluk çağ önlenebilir körlüklerin önemli bir sebebi olup, dünyada her yıl 50000 çocuğun, PR nedeniyle kör olduğu bildirilmektedir. Dünya Sağlık Örgütü, VISION 2020 isimli programında, önlenebilir körlükler arasında, PR'ye bağlı körlüklerin önlenmesine özellikle vurgu yapmaktadır $(1,2)$.

Prematür doğan bebekte, hele ki ek oksijen ihtiyacı gelişirse, PR gelişme ihtimali artar. PR gelişmesinde, diğer risk faktörleri, düşük doğum ağırlığı, düşük gestasyonel yaş, kan transfüzyonları, asidoz, periventriküler, intraventriküler kanama, respiratuvar distres sendromu, surfaktan tedavisi ihtiyacı sayılabilir (2-4). PR insidansı, doğum ağırlığı ve doğum kilosu ile ters orantılıdır (4). Gelişmekte olan ülkelerde, gelişmiş ülkelere göre daha büyük doğum ağırlığına ve doğum haftası yaşına sahip bebeklerde PR gelişmektedir $(1,2)$. Bu

\begin{tabular}{|c|c|}
\hline & ORCID No \\
\hline Göksu ALAÇAMLI & 0000-0001-5013-9981 \\
\hline Sema TAMER KADERLİ & $0000-0003-4851-6527$ \\
\hline Aylin KARALEZLİ & 0000-0003-1316-4656 \\
\hline Nilay HAKAN & $0000-0002-6575-7640$ \\
\hline Başvuru Tarihi / Received: & 16.12 .2020 \\
\hline Kabul Tarihi / Accepted : & 07.01 .2021 \\
\hline Adres / Correspondence : & Göksu ALAÇAMLI \\
\hline $\begin{array}{l}\text { Muğla Eğitim ve Araştırma } \\
\text { Muğla }\end{array}$ & Hastanesi, Göz Hastalıkları Kliniği, \\
\hline e-posta / e-mail & GOKSUALACAMli@yahoo.com \\
\hline
\end{tabular}

\begin{abstract}
To evaluate the results of the retinopathy of prematurity in the babies who have been referred to our ophthalmology clinic and have the history of premature birth in Mugla. Babies who have born under 32 weeks of gestational age or above 32 weeks of gestational age but had risk in clinical follow up was screened. Total 949 examinations were applied to 486 babies who was screened between years 20142019 . Retinopathy of prematurity was found $8 \%$ in any stage. Only one baby needed therapy. The best method to avoid the blindness caused from retinopathy of prematurity is screening the babies in the risk groups properly. Then, it is possible to avoid the blindness caused from retinopathy of prematurity by treating the babies on the right time and in a efficient way, detecting the ones who deserve the therapy for retinopathy of prematurity.
\end{abstract}

Keywords: Follow-up, Retinopathy of Prematurity, Staging yüzden, her ülkenin farklı sosyoekonomik şartları, yeni doğan ölüm oranı sayıları, yeni doğan yoğum bakım ünitesi şartları olduğu gerçeğine dayanarak, ülkelerin, kendilerine ait PR tarama rehberi olması gerekmektedir. Hatta aynı ülke içinde, yukarıda belirtilmiş olan yöresel farklı şartlardan ötürü, farklı bölgelerin PR oranlarının farklı olabileceği de göz önünde bulundurulmalıdır $(1,2)$. Ülkemizde son 5 yılda geniş vaka serileriyle yapılan çalışmalarda, taranan popülasyonun özelliklerine bağlı olarak, PR gelişme ve tedavi gereksinimi olan ciddi PR sıklıkları sirasıyla \%23.0-75.5 ve \%5.0-59.1 gibi değişken oranlarda bildirilmiştir. Ülkemizden son dönemde yayınlanan çok merkezli bir çalışmada 15745 prematüre bebeğin taranması sonucu herhangi bir evre PR gelişim oranı ve ciddi PR gelişim oranı sırası ile $\% 30$ ve $\% 5$ olarak bulunmuştur (6).

Biz de bu çalışmamızda, kliniğimizdeki son 5 yıllık takip sürecimizde prematür doğan bebek taramalarında saptanan PR sıklığını, retrospektif olarak araştırmayı planladık.

\section{Gereç ve Yöntem}

Muğla Sitk1 Koçman Üniversitesi Klinik Araştırmalar Etik Kurul, 02/07/2020 tarihli 07/II sayılı karar formu ile etik kurul onayı alınmıştır. Mayıs 2014- Nisan 2019 arasında, Muğla Sitk1 Koçman Üniversitesi Eğitim ve Araştırma Hastanesi Yenidoğan Yoğun Bakım ve/veya Polikliniği'nden, Göz Hastalıkları Polikliniği'ne yönlendirilen, öyküsünde 32 hafta altında gestasyonel yaşı olan 
bebeklerin tümü ve 32 hafta üstünde gestasyonel yaşı olan, fakat neonatolog ya da pediatrist tarafindan klinik olarak riskli bebek olarak değerlendirilen tüm bebeklerin post natal 4 . haftalarındaki oftalmoskopik muayenelerine ait dosyalar, retrospektif olarak incelendi. Hastanemiz Yenidoğan Yoğun Bakım Ünitesinde takip edilmemiş olup da, diş merkezlerde takip edilen ve doğumdan sonraki 4. haftada hastanemiz Yenidoğan Polikliniği'ne başvuran bebeklerin de, postnatal 4 . haftasındaki oftalmoskopik muayenelerine ait dosyalar da, retrospektif olarak incelendi.

Taramalar, Muğla Sıtkı Koçman Üniversitesi Eğitim ve Araştırma Hastanesi Göz Hastalıkları Polikliniği ya da polikliniğe gelemeyecek düzeyde riskli bebeklerde Yenidoğan Yoğun Bakım Ünitesinde gerçekleştirildi. Oftalmoskopik muayeneden $45 \mathrm{dk}$. önce bebeklerde beslenme, aspirasyon riskini önlemek için kesildi. Tarama öncesinde, retina ve vitreusun iyi görülebilmesi için pupil dilate edildi (midriazis). Muayeneden 1 saat önce midriazis işlemine başlandı. Bir damla $\% 0.5$ 'lik tropikamid damladan 5 dakika sonra, $\% 2.5$ 'luk fenilefrin damla ile pupilla genişletildi. Son damladan sonra 45-60. dakika sonra, topikal anestezi sağlamak için, bir damla Proparakain hidroklorid (\%0.5) damla damlatıldıktan sonra, her hasta için otoklavda ayrı steril edilen göz kapağı spekulumu ve sklera indentörü kullanıldı. Binoküler indirekt oftalmoskop ile muayene yapıldıktan sonra, ayrıntılı olarak zon, evre, yayılım ve "plus" hastalık olup olmadığını not edilip, tedavi planı ve bir sonraki muayenenin tarihini belirtildi. Muayene esnasında bebeğin bir hemşire tarafından başı ve kolları sabitlenecek şekilde tutuldu.

\section{Bulgular}

Mayıs 2014- Nisan 2019 arasında, toplamda 486 bebek tarandi. Bu bebeklere, klinik takip açısından lüzum üzerine toplamda 949 mükerrer muayene yapildi.

PR tanısı alıp da, tedavi endikasyonu almayan olgular, spontan remisyon görülene kadar kliniğimizde takip edildi. Laser endikasyonu alan olgu, kliniğimizde halen laser cihazı bulunmaması sebebiyle, laser tedavisi için dış merkeze yönlendirildi. $\mathrm{Bu}$ olgunun, müteakip takipleri kliniğimizde yapıldı. Bu olguda, ek laser ihtiyacı saptanmadi.

Herhangi bir evrede PR, ortalama $\% 8$ olarak belirlendi. Toplamda $41(\% 8)$ bebekte PR saptand1.41 bebek içinde, sadece 1 bebek, laser fotokoagulasyon için dış merkeze yönlendirildi. Tablo 1'de senelere göre PR saptanan bebeklerin, sayıları ve yüzdeleri gösterilmektedir. Tablo 2'de evrelerine göre saptanan PR sayıları ve yüzdeleri gösterilmektedir.

\section{Tartışma}

Hastalığın patogenezindeki en önemli unsur bebeğin erken doğması ile anne karnındaki göreceli olarak hipoksik ortamın bozulması sonucu bebek retinasında başlayan hiperoksik sürecin devamında hipoksik fazın oluşturduğu proliferasyon ile gelişen neovaskülarisyon ve beraberinde oluşan retinal anormalliklerdir. Çoğu prematür bebekte, bulgular kendiliğinden gerilese de, bazı bebeklerde, yakın takip hatta tedavi gerekebilir. Bu süreçte en fazla suçlanan mediatör ise, vaskülerendotelial büyüme faktörüdür (VEGF) (2,3,6-8).

Ülkemizde, Türk Neonatoloji Derneği ve Türk Oftalmoloji Derneği tarafından 2016'da yayınlanan rehberde önerilen tarama kriterleri aşağıdaki gibidir (9).

Gebelik yaşı $(\mathrm{GY}) \leq 32$ hafta veya $\mathrm{DA} \leq 1500$ gram doğan tüm bebekler ile GY>32 hafta veya DA>1500 gram olup kardiyopulmoner destek tedavisi uygulanmış veya "bebeği takip eden klinisyenin PR gelişimi açısından riskli gördüğü” preterm bebeklerin taranması uygundur. Taramalar, doğumdan sonra (post natal) 4. haftada yapılmalıdır.

Prematüre bebeğin PR açısından izlem şeması ilk muayenedeki bulgulara göre şekillendirilir. İlk muayenede retinopati geliştiği saptanırsa hastalığın şiddetine ve ilerleme hızına göre izlem takvimi oluşturulur. Retinal vaskülarizasyon zon III'de ise 2-3 haftada bir, zon II'de ise en az 2 haftada bir muayene tekrarlanır. Zon I'de ise ilerleme gösterip göstermediğine göre haftada en az bir kez muayene ile izlenir ve bulgularda kötüleşme saptanırsa veya preplus hastalık saptanırsa muayeneler izleyen hekimin gerek gördüğü şekilde sıklaştırılır. Günümüzde dijital ortamda retina görüntüleri alabilen cihazlar kullanıma girmiştir. Bu yöntem retina bulgularının bilgisayar ortamında kayıt altına alınmasında, PR eğitiminde ve uzaktan konsültasyonda kullanmak için faydalı olabilir. Ancak izlem, izlemin sonlandırılması ve tedavi kararı binoküler oftalmoskop ile muayene sonucuna göre alınmalıdır. Dijital fotoğraf görüntüsü alan ve kaydeden cihazların sensitivitesi, avantajları ve kullanıma girmesinin değerlendirilmesi için ileri çalışmalara ihtiyaç vardır. Bununla birlikte bu cihazlar indirekt oftalmoskopik muayeneyi tamamlayıcı, takiplerde bire bir karşılaştırma amaçlı ve medikolegal açıdan kanıt olabilmesi açısından önem taşımaktadır. İlk muayene neonatolog/pediatrist sorumluluğundadır. İzlemin aralığı, süresi ve tedavi kararını oftalmolog verir. Tarama muayeneleri PR gerileyene kadar veya tam retinal damarlanma tamamlanıncaya kadar devam eder. İleri takip ve tedavi gerektiren vakaların ilgili hekime/kliniğe yönlendirilmesini göz hekimi yapar (9).

Ülkemizde son 5 yılda geniş vaka serileriyle yapılan çalışmalarda, taranan popülasyonun özelliklerine bağlı olarak, PR gelişme ve tedavi 
gereksinimi olan ciddi PR siklıkları sırasıyla \%23.075.5 ve \%5.0-59.1 gibi değişken oranlarda bildirilmiştir. Ülkemizden son dönemde yayınlanan çok merkezli bir çalışmada 15745 prematüre bebeğin taranması sonucu herhangi bir evre PR gelişim oranı ve ciddi PR gelişim oranı sırası ile $\% 30$ ve $\% 5$ olarak bulunmuştur (6).

Tablo 1: Yıllara göre PR saptanan bebeklerin, sayıları ve yüzdeleri

\begin{tabular}{|c|c|c|c|c|c|c|}
\hline Yıl & $\begin{array}{c}\text { Taranan } \\
\text { Bebek Sayısı }\end{array}$ & $\begin{array}{l}\text { Mükerrer } \\
\text { Muayene } \\
\text { Sayısı }\end{array}$ & $\begin{array}{l}\text { Herhangi Bir } \\
\text { Evrede PR } \\
\text { Görülme } \\
\text { Sayısı } \\
\end{array}$ & $\begin{array}{c}\text { PR Görülme } \\
\text { Oranı }\end{array}$ & $\begin{array}{c}\text { Laser Fotokoagulasyon } \\
\text { Gereksinimi Olan Bebek } \\
\text { Sayısı }\end{array}$ & $\begin{array}{c}\text { Cerrahi } \\
\text { Gereksinimi Olan } \\
\text { Bebek Sayısı }\end{array}$ \\
\hline 2014 & 7 & 15 & 0 & $\% 0$ & 0 & 0 \\
\hline 2015 & 55 & 145 & 6 & $\% 10$ & 1 & 0 \\
\hline 2016 & 60 & 119 & 7 & $\% 11$ & 0 & 0 \\
\hline 2017 & 157 & 299 & 16 & $\% 10$ & 0 & 0 \\
\hline 2018 & 175 & 324 & 10 & $\% 5$ & 0 & 0 \\
\hline 2019 & 32 & 45 & 2 & $\% 6$ & 0 & 0 \\
\hline $\begin{array}{c}2014-2019 \\
\text { Toplam }\end{array}$ & 486 & 949 & 41 & $\% 8$ & 1 & 0 \\
\hline
\end{tabular}

Tablo2: Evrelerine göre saptanan PR sayıları ve yüzdeleri

\begin{tabular}{|c|c|c|c|}
\hline Yil & Evrelerine Göre PR & $\begin{array}{c}\text { Evrelerine Göre Saptanan PR } \\
\text { Sayıları } \\
\end{array}$ & $\begin{array}{c}\text { Evrelerine Göre Saptanan PR } \\
\text { Sayıları Toplamı }\end{array}$ \\
\hline 2014 & 0 & 0 & 0 \\
\hline \multirow{4}{*}{2015} & Zon 3, Evre 1 & 1 & \multirow{4}{*}{6} \\
\hline & Zon 3, Evre 2 & 3 & \\
\hline & Zon 3, Evre 3 & 1 & \\
\hline & Zon 2, Evre 3, Plus Hastalik & 1 & \\
\hline \multirow{2}{*}{2016} & Zon 3, Evre 1 & 4 & \multirow{2}{*}{7} \\
\hline & Zon 3, Evre 2 & 3 & \\
\hline \multirow{2}{*}{2017} & Zon 3, Evre 1 & 14 & \multirow{2}{*}{16} \\
\hline & Zon 2, Evre 2 & 2 & \\
\hline \multirow{2}{*}{2018} & Zon 3, Evre 1 & 6 & \multirow{2}{*}{10} \\
\hline & Zon 2, Evre 2 & 4 & \\
\hline \multirow{2}{*}{2019} & Zon 3, Evre 1 & 1 & \multirow{2}{*}{2} \\
\hline & Zon 2, Evre 2-3, Plus Hastalık & 1 & \\
\hline
\end{tabular}

Kliniğimizde, Mayıs 2014- Nisan 2019 arasında taranan bebeklerdeki PR oranının (\%8), Türkiye'de önceden yapılmış tarama sonuçlarında elde edilen oranlara göre daha az olduğunu tespit ettik (13). Bunu, hastanemize ait Yeni Doğan Yoğun Bakım Ünitesi'nin, 2.Basamak Yeni Doğan Yoğun Bakım Ünitesi olmasına ve de Oftalmoloji Kliniği'nin PR için henüz sadece bir tanı merkezi olup, tedavi merkezi olmamasına bağladık. 2. Basamak Yeni Doğan Yoğun Bakım Ünitelerinde, 32 hafta öncesi doğumlar takip edilmemektedir.

Sadece bir tanı merkezi olmamıza rağmen, kliniğimizde, son 5 yılda, hatırı sayılır düzeyde PR açısından riskli bebek taraması yapılmıştır. Yeni Doğan Yoğun Bakım Ünite'mizin 3. basamak olmas1 ve/veya Oftalmoloji Kliniği'mizin PR için tedavi merkezi olmasından sonra, PR açısından çok daha fazla sayıda ve de çok daha düşük gestasyonel haftalı bebekler tarayacak olmamız olasıdır.

PR için, dünyadaki halen mevcut olan 3 . epidemiyi azaltmak açısından, standart bir tarama ve tedavi çerçevesi oluşturmak, hem Dünya Sağlık Örgütü'nün hem de Sağlık Bakanlığı'mızın öncelikli programlarından olup, önlenebilir körlük sebebi olan PR'ye bağlı körlüğü azaltmada en önemli hedef, tedavi gerektirecek bebeklerin en k1sa sürede tedavi merkezlerine yönlendirilmesidir (1,2,7-9).
Etik Kurul Onayı: Muğla Sitkı Koçman Üniversitesi Klinik Araştırmalar Etik Kurulu 02/07/2020 tarihli 07/II sayılı yazı ile izin alınmıştır.

\section{Kaynaklar}

1. Kara C, Petriçli Seza İ. Prematüre retinopatisi klinik tanı ve sinıflama. Güncel Retina. 2018;2(1):21-8.

2. Gilbert C, Foster A. Childhood blindness in the context of VISION 2020 - the right to sight. Bull World Health Organ. 2001;79(3):227-32.

3. Özcan A, Soylu M, Demircan N ve ark. Prematüre retinopatisi gelişiminde risk faktörleri ve tedavi sonuçları. Turk J Ophthalmol. 1993;100:230-73.

4. Zhang $\mathrm{HB}$, Wang $\mathrm{XD}$, Xu K, et al., The progress of prophylactic treatment in retinopathy of prematurity. Int $\mathrm{J}$ Ophthalmol. 2018, 18;11(5):858-73.

5. Gilbert C. Retinopathy of prematurity: A global perspective of the epidemics, population of babies at risk and implications for control. Early Hum Dev. 2008;84(2):77-82.

6. Öztürk T, Retinopathy of Prematurity in Turkey and in the World: How Big is the Problem? Turk J Retina-Vitreous. 2015;23:145-50.

7. Palmer EA, Flynn JT, Hardy RJ, et al., Incidence and early course of retinopathy of prematurity. The Cryotherapy for Retinopathy of Prematurity Cooperative Group. Ophthalmology. 1991;98(11):1628-40.

8. Early Treatment For Retinopathy Of Prematurity Cooperative Group. Revised indications for the treatment of retinopathy of prematurity: results of the early treatment for retinopathy of prematurity randomized trial. Arch. Ophthalmol. 2003;121(12):1684-94.

9. Türkiye Prematür Retinopatisi Rehberi, 2016, http://www.neonatology.org.tr/wpcontent/uploads/2016/12/prematur retinopatisi rehberi.pdf. 